\title{
Premenstrual Syndrome and Premenstrual Dysphoric Disorder: Symptoms and Cluster Influences
}

\author{
Faustino R. Pérez-López ${ }^{*}, 1$, Peter Chedraui ${ }^{2}$, Gonzalo Pérez-Roncero ${ }^{1}$, María T. López-Baena ${ }^{1}$ and \\ José L. Cuadros-López ${ }^{3}$ \\ ${ }^{I}$ Department of Obstetrics and Gynecology, University of Zaragoza Faculty of Medicine, Zaragoza, Spain \\ ${ }^{2}$ Institute of Biomedicine, Universidad Católica de Santiago de Guayaquil, Guayaquil, Ecuador \\ ${ }^{3}$ Obstetrics and Gynecology Service, University of Granada Faculty of Medicine, San Cecilio Hospital, Granada, Spain
}

\begin{abstract}
Many women in their reproductive years experience some mood, behavioral, or physical symptoms in the week prior to menses. Women experiencing mild symptoms may have a wide variability in the level of symptom burden, whereas a minority suffers severe and debilitating symptoms. Severe premenstrual syndrome (PMS) affects $3 \%$ to $5 \%$ of women of reproductive age and has been classified under the Diagnostic and Statistical Manual of Mental Disorders (DSM IV) as premenstrual dysphoric disorder (PMDD). Both disorders are characterized mainly by symptoms confined to the premenstrual period, which reduce not only patients' quality of life, but also their working activities. Women suffering PMDD experience severe dysphoric mood, and a greater desire and actual intake of certain foods, demonstrating impaired cognitive performance during the luteal phase. Several theories have been proposed to explain the underlying mechanisms of PMS and PMDD with complex bio-psycho-social factors involved. Although precise causes are unknown, the late luteal phase could be associated with diverse psychosomatic and behavioral symptoms appearing premenstrually which should be appropriately treated. Notwithstanding this high prevalence, no specific symptoms or signs appear, nor have any recognizable anatomical factors been identified in women suffering PMS or PMDD, and hence, no universal treatment yet exists. Despite this, therapeutic progress has been reached, although the ideal treatment has not yet been obtained due to the many clusters involved.
\end{abstract}

Keywords: Premenstrual syndrome, Premenstrual dysphoric disorder, Psychosomatic gynecology, Drospirenone, Selective serotonin reuptake inhibitors, GABA.

\section{INTRODUCTION}

The premenstrual syndrome (PMS) and premenstrual dysphoric disorder (PMDD) constitute psychosomatic gynaecological paradigms. They share some endocrine and nervous system causes, nutritional influences and psychosocial factors. All complaints are associated to increased costs -more indirect than direct- due to loss of work days and reduced productivity. Furthermore, they cause interpersonal problems that erode health, social and family relationships [1-6]. Although physical discomfort and mood changes related to menstruation have been known since Hippocrates times, it has taken quite long to reach a PMS definition. In 1931, Frank described 15 women with severe premenstrual symptoms proposing the concept of premenstrual tension. In 1953, Greene and Dalton introduced the term premenstrual syndrome, proposing an imbalance between estrogens and progesterone during the luteal phase as the biological cause, and used progesterone as a therapeutical option. The syndrome is a complex condition that includes up to 200 symptoms, but the most frequent are irritability, breast tenderness and dysphoria, among others. Its basic clinical

*Address correspondence to this author at the Department of Obstetrics and Gynecology, University of Zaragoza Faculty of Medicine, Domingo Miral s/n, Zaragoza 50009, Spain; E-mail: faustino.perez@unizar.es hallmark is the temporary presence of symptoms which appear in the luteal phase, and are reduced during menstruation and disappear in the follicular phase. In 1987, the American Psychiatric Association introduced in the Diagnostic and Statistical Manual of Mental Disorders (DSM) III-R, the concept of late luteal phase dysphoric disorder to conjunctly group all temporary changes in behavior [7]. In the fourth DSM edition (DSM-IV), nomenclature changed to premenstrual dysphoric disorder (PMDD) maintaining almost the same criteria [8]. PMDD defines a narrow group of women with the most severe emotional symptoms and functional impairment which are exacerbated premenstrually.

Emotional symptoms are frequent in moderate to severe PMS, but it also includes physical symptoms (Table 1). Contrarily, emotional symptoms predominate in PMDD. In the DSM-IV list, 10 of 11 are emotional and behavioral in nature, while one includes multiple common physical symptoms (Table 2). The diagnosis of PMDD requires 5 of the 11 specific symptoms that define its dysphoric nature. Symptoms must also meet the following requirements: 1) be present during most of the time of the week previous to menstruation, reduce on menstruation, disappear during the week following menstruation and affect the majority of cycles of a year; 2) symptoms must interfere with personal and social relationships; 3) the alteration is not an 
exacerbation of an emotional or physical symptom; and 4) the criteria must be confirmed by a diary over at least two consecutive menstrual cycles [3]. However, there is a significant intra-patient variability in terms of PMDD symptom duration and time-to-onset and offset [9]. Findings during physical examination are usually unremarkable. Mild edema of the ankles, feet, and fingers may occur secondarily to fluid retention. Breast tenderness may also be present. Women with PMDD express dysphoric mood and a greater desire and actual intake of certain foods and have an impaired cognitive performance during the luteal phase.

Table 1. Diagnostic Criteria for Premenstrual Syndrome (ICD10) According to the World Health Organization

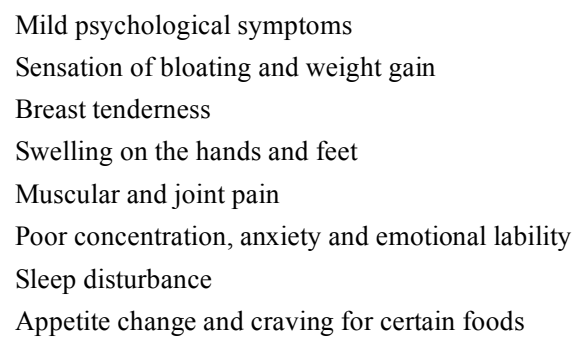

Limits between PMS and PMDD are not precisely defined and may possibly constitute a "continuous" pathophysiological process. The diagnosis of both PMS and PMDD is established by exclusion of other diseases. However, it seems that PMDD is a distinct clinical disorder than the PMS. The key criterion for PMDD diagnosis is the interference with social and occupational functioning, to distinguish it from the less severe PMS. PMDD has also been considered a variant of depressive disorders in which premenstrual psycho-biological changes would exacerbate mild or atypical depressive symptoms [10]. Nevertheless, considerable controversy exists in relation to the PMS and the PMDD status, its pathophysiology, diagnostic characteristics and therapeutical standards, as well as their social, industrial, ideological and political consequences. Moreover important to mention is the fact that many taboos have been linked to menses. Some investigators suggest that PMDD has been marketed by pharmaceutical companies to increase the therapeutical demand $[11,12]$. In 2003, fluoxetine manufacturer was required by The European Agency for the Evaluation of Medicinal Products to remove PMDD from the list of indications for fluoxetine sold in Europe [13]. In Australia, although PMDD is officially recognized, SSRIs are not subject to reimbursement under the Pharmaceutical Benefits Scheme [14].

\section{PREVALENCE}

PMS prevalence during life span may vary from 75 to $85 \%$ of women if an isolated symptom is considered, between 10 and $15 \%$ when cases request medical assistance, and from $2 \%$ and $8 \%$ if interruption of social activity is referred $[15,16]$. In the United Kingdom, current estimates are that approximately 800,000 severe PMS cases exist, many of which are PMDD [17]. In addition, PMS may take a long time to be properly diagnosed and treated. Kraemer and Kraemer [2] have reported that 220 out of 492 women have doctor shopped, seeing an average 3.75 physicians over an average interval of 5.33 years before being diagnosed with PMS and/or effectively treated to alleviate their symptoms. The syndrome affects women with normal ovulatory functions; its greatest incidence is among women aged 25 and 40 , sometimes having a background of depressive or mood disorders, often with at least one previous birth, and in some cases with postpartum depression. In women with severe (six symptoms) or moderate PMS (one to five symptoms), there is a high level of intraindividual variation over time. Thus, $72 \%$ of women demonstrate fluctuation in their PMS status [18].

Reported PMDD prevalence may in fact be overestimated due to overdiagnosis [19] which may create psychological and social problems and also lead to unnecessary prolonged pharmacologic therapy [20]. The low specificity of symptoms frequently contributes to this misinterpretation; thus, other disorders should carefully be excluded. On the other hand, some studies show that the premenstrual period is phase that increased the risk for the exacerbation of psychiatric disorders such as obsessivecompulsive behavior, increased alcohol consumption, higher suicide rate or admission of symptomatic schizophrenics. PMDD is associated with low educational level, a history of major depression and current addiction to smoking, and its prevalence increases in the premenopausal phase $[15,21]$.

Table 2. Symptoms Required PMDD Diagnosis in Most Menstrual Cycles During the Past Year, Five (or More) of the Following Symptoms were Present for Most of the Time During the Last Week of the Luteal Phase, Began to Remit within a Few Days After the Onset of the Follicular Phase, and were Absent in the Week Post-Menses. At Least One of the Symptoms Being Either 1, 2, 3 or 4 (Major Criteria)

\begin{tabular}{|l|l|}
\hline \multicolumn{1}{|c|}{ Major Criteria } & \multicolumn{1}{|c|}{ Minor Criteria } \\
\hline \hline $\begin{array}{l}\text { 1. Depressed mood, feelings of hopelessness, or self-depreciating thoughts } \\
\text { 2. Anxiety, tension }\end{array}$ & 5. Lack of interest in everyday activities, anhedonia \\
$\begin{array}{l}\text { 3. Mood changes, emotional instability (feeling suddenly sad or tearful or } \\
\text { increased sensitivity to rejection) }\end{array}$ & $\begin{array}{l}\text { 7. Lethargy, easy fatigability, or marked lack of energy } \\
\text { 4. Irritability, anger or increased interpersonal conflicts }\end{array}$ \\
& 8. Change in appetite, overeating, or specific food cravings \\
& 10. Subjective sense of being out of control or overwhelmed \\
& 11. Physical symptoms: headaches, arthralgia, myalgia, weight gain, \\
&
\end{tabular}


Premenstrual mood symptoms did not exhibit familial aggregation in families with bipolar or major depressive disorders [22]. PMDD women have more stressful events and their daily life stressors have a greater impact on their lives than non-PMDD women [23, 24]. PMDD women also report more traumatic life stress, including sexual and physical abuse $[21,25]$. Due to stressful or traumatic events, women may have an impaired stress response, being PMDD women more vulnerable [24, 26, 27].

Obesity is strongly associated with PMS. Thus, obese women (BMI $\geq 30$ ) have nearly a three-fold increased risk for PMS than non-obese ones. In addition, PMS is more prevalent among Caucasian, younger and smoking women [28].

\section{PATHOPHYSIOLOGY OF THE PREMENSTRUAL SYNDROME AND PREMENSTRUAL DYSPHORIC DISORDER}

Symptoms related to menstruation are multidimensional and affect different physiological systems. PMS is characterized by an imbalance of complex interactions of hormones, essential nutrients and neurotransmitters, in combination with psycho-social stress. These unbalanced conditions vary from one person to another, and in the same person from one cycle to another. Homeostasis alterations and deficient adaptation constitute the nucleus of the pathophysiological mechanism $[16,29]$. PMDD is also a cluster of genetic, emotional, motivational, cognitive and behavioral changes which occur in regular association immediately prior to/ or during the early menstrual days.

\section{Genetic Influences}

During the last years, there has been a growing interest to determine if premenstrual mood symptoms, either PMS or PMDD, exhibit familial aggregation or some degree of heritability. Some behavioral characteristics, including personality, cognitive capacities and susceptibility to emotional and mental disorders have been postulated to be linked to genetic polymorphisms. Changes in psychiatric phenotypes due to genetic factors are seldom the result of gene polymorphisms [30,31]. Preliminary studies have reported that there is no evidence for a specific genetic contribution in the risk of suffering PMS due to the unreliability in measuring premenstrual symptoms. However, self-reported PMS symptoms are different in monozygotic twins and in dizygotic ones [32].

Kendler et al. [33] used a twin-measurement model that allows estimation of the causative roles of genetic and environmental factors with correction for measurement errors or short-term temporal fluctuations. In 1, 312 menstruating female twins followed-up over 6 years, retrospectively reported that premenstrual-related depressive and anxiety symptoms are moderately stable over time and are substantially heritable. The relative contribution of genes to premenstrual symptoms and the extent of genetic and environmental co-variation with the personality trait neuroticism and lifetime major depression have been studied in an Australian monozygotic and dizygotic twin cohort [34]. Although there were genetic correlations between reported
PMS and neuroticism, and with lifetime major depression, there was a $39 \%$ PMS genetic variance that was not explained by these factors.

Preliminary results have demonstrated that women with prospectively diagnosed PMDD were associated with estrogen receptor alpha gene (ESR1) genetic variation [35]. Women with PMDD differ from symptom-free subjects in terms of serotonin-related biological markers. However, women with prospectively diagnosed PMDD, as compared to healthy controls, did not display associations between the disease and polymorphisms that encode the 5hydroxytryptamine transporter, tryptophan hydroxylase 1 , and monoamine oxidase A. These results do not support a significant role for studied marker polymorphisms [36].

Polymorphism of the serotonin receptor 1A C(-1019)G was studied in women with PMDD and healthy control subjects. Despite the postulated high risk G/G, there was a marked overrepresentation of the $\mathrm{C} / \mathrm{C}$ genotype in women suffering PMDD, being the $\mathrm{C}$ allele a contributing risk for PMDD [37]. The transcription factor AP-2 family, which is involved in the regulation of the monoaminergic system, has been postulated as a risk factor for PMDD. However, genotype frequencies did not differ between women with PMDD and controls [30, 31].

\section{Steroid Hormone Influences}

Attempts have even been made to relate PMS symptoms with estrogen/progesterone levels and the estrogen/progesterone ratio. It is considered that progesterone presence at the beginning of the luteal phase is essential for PMS to occur. In the case of PMDD, the results failed to find any correlation between anxiety and depression when compared to estrogen/progesterone levels [4, 38, 39].

Estrogen might influence the serotonin system, producing a positive mood and wellbeing, whereas progesterone decline, characteristic of the late luteal phase had been linked to changes in the central nervous system in terms of gammaamino-butyric acid (GABA) and progesterone metabolites that interact with the $\mathrm{GABA}_{\mathrm{A}}$ receptor complex [40-43]. Bilateral ovariectomy or treatment with gonadotrophin releasing hormone $(\mathrm{GnRH})$ agonists followed by progesterone treatment can induce premenstrual symptoms, while progesterone treatment during the luteal phase is devoid of benefits over premenstrual symptoms $[44,45]$.

Estrogens and progesterone also interact with the reninangiotensin-aldosterone system (RAAS) which controls hydromineral balance. Estrogens could stimulate the RAAS, increasing angiotensinogen synthesis in the liver, this being responsible for bloating and weight gain [46]. Aldosterone competes with progesterone at the receptor level causing an antimineralocorticoid effect manifested as a dominant natriuresis during days of increased progesterone secretion [47]. The majority of synthetic progestagens do not have the antimineralocorticoid effect of progesterone; nevertheless drospirenone, a recently developed progestagen, has the same antimineralocorticoid effects as progesterone and is effective in the treatment of symptoms associated with premenstrual bloating [48]. The combined anovulatory drug 
which includes this progestagen is specially useful in cases of PMS and cyclic liquid retention [49].

Allopregnanolone, a metabolite of progesterone, serves in homeostatic mechanisms restoring normal GABAergic and hypothalamic-pituitary-adrenal functions following stress. Animal models indicate that this neuroactive steroid may be related to PMS/PMDD pathophysiology. It is a neuroactive steroid with contradictory effects. Thus, anesthetic, sedative and anxiolytic as well as aggressive and anxiogenic properties have been reported [42, 43, 50].

In women, allopregnanolone fluctuates during the menstrual cycle [51]. Luteal phase serum alloprenanolone levels are lower in PMS patients as compared to controls. Serum progesterone levels are lower in PMS women in both the follicular and luteal phase while serum estradiol levels are in the normal range in both groups [52]. The relative low levels of both allopregnanolone and progesterone may be associated with inadequate neuroactive steroid production which impairs response to stressful conditions. As compared to controls, women with PMDD had greater luteal phase serum allopregnanolone and lower cortisol levels during both basal condition and under mental stress. In addition, PMDD women had a greater allopregnanolone/progesterone ratio than control subjects [53]. In fertile women, progesterone induces adverse mood, related to allopregnanolone serum concentrations, equivalent to an inverted U-shaped curve. This effect may be similar when progesterone is added to postmenopausal women hormone treatment. In this model, negative mood symptoms occur when serum allopregnanolone concentrations are similar to endogenous luteal phase levels, while low and high concentrations have less effect on mood. The maximal effective allopregnanolone concentration capable of producing negative mood is in the range serum luteal phase concentrations [54].

Serum allopregnanolone levels are reduced in the luteal phase of women with PMS causing an inability to increase GABA levels in the CNS required during states of excitability as occurs during ovulation and physical and psychological stress [51]. Low levels of this progesterone metabolite favour disorders such as anxiety, tension and depression. The reduced basal levels of progesterone and allopregnanolone in the luteal phase are accompanied by high dehydroepiandrosterone (DHEA) and free testosterone levels which contribute to cyclic bouts of anxiety, aggressiveness and irritability that occur in patients with PMS [54]. However, not all studies agree regarding blood allopregnanolone levels [55].

Symptomatic women would have an inadequate allopregnanolone response to stress due to reduced functional sensitivity of the $\mathrm{GABA}_{\mathrm{A}}$ receptor [24]. Additionally, rodent stress studies that involve social isolation find irregularities in GABA activity [56]. Severe life stress may result in alterations in the $\mathrm{GABA}_{\mathrm{A}}$ receptor function in women with PMDD [57, 58].

\section{Neurotransmitters and the Nervous System Function}

One of the most controversial aspects of PMS refers to the effects of ovarian hormones on the central nervous system. In PMS there is a relationship between low estradiol levels during the luteal phase and lower brain noradrenergic activity during ovulation and the luteal phase. The low levels of norepinephrine in women with PMS correlate negatively with sudden changes of mood, impatience, nervousness, tiredness, weakness, apathy and headache [59]. Platelet alpha-2 adrenergic receptor is involved in anxiety and depressive disorders. In PMDD women, there were no differences in platelet binding parameters between phases of the menstrual cycle; although receptor density correlated positively with symptom severity during the luteal phase [60].

Serotonin plays a central role in the aetiopathogenesis of PMS and PMDD; specially as an expression of irritability and anger, symptoms of depression, and the craving for specific foods found in PMDD sufferers. Estrogens increase cerebral serotonin receptor density and the sensitivity toward serotonin agonists. PMDD women had higher serotonergic function in the follicular phase but lower in the luteal phase, compared to women with PMS without PMDD and normal controls, suggesting a relevant role for serotonin function alterations in women with PMDD [61]. The role of this neurotransmitter is reinforced by the clinical effectiveness of selective serotonin re-uptake inhibitors (SSRIs) in the treatment of PMDD [62, 63].

During the menstrual cycle, gonadal steroids are also involved in GABA neuronal function modulation. In animals, estradiol enhances excitatory neurotransmission while progesterone-derived neurosteroids produce GABAergic inhibition. Brain GABA content fluctuates along the menstrual cycle in both healthy and PMDD women [64]. PMDD women display increased cortical GABA from the follicular phase until half way through or the end of the luteal phase [65]. These results suggest that the GABAergic system is modulated by ovarian steroids and these changes could be important in the pathogenesis of PMDD.

Glutamate fluctuations across the menstrual cycle in the medial prefrontal cortex of PMDD women and healthy controls have been demonstrated with proton magnetic resonance spectroscopy. PMDD women may display an increased sensitivity to phase-related alterations of the menstrual cycle [66]. Alterations in pain threshold have also been associated with the severity of symptoms [67].

Grey matter regional variation over the menstrual cycle has been studied by magnetic resonance imaging. In the postmenstrual period, grey matter is relatively increased in the right anterior hippocampus and relatively decreased in the right dorsal basal ganglia [68]. These results show human brain plasticity associated with endogenous hormone fluctuations and clinical symptoms.

The autonomic nervous system may also play a crucial role in controlling body response to external and internal stimuli, maintaining nearly every important body homeostatic process. Some classical studies demonstrated that parasympathetic nerve activity in PMS women was lower in the late luteal phase than in the follicular phase [69]. Venous oxygenation index, as expression of autonomous nervous system alteration, is significantly decreased in PMS women [70]. PMDD women had elevated norepinephrine and total peripheral resistance at rest and during mental stressors compared with control subjects; 
and these phenomena were present in both follicular and luteal phases [71]. In addition, PMDD women have reduced vagal tone compared to controls, this difference being more apparent in the non-symptomatic follicular phase [72]. Therefore, instability or slight disequilibrium of the autonomic system may induce reiterative premenstrual symptomatology. The cluster of symptoms, thus, may differ among women and even within each but may also fluctuate between their menstrual cycles.

In the luteal phase, women with severe PMS have decreased parasympathetic activity during sleep in association with their premenstrual symptoms as compared to the follicular phase when they have less or no symptoms [73]. Although women with severe PMS report poor subjective sleep quality during the luteal phase, polysomnograms did not detect specific sleep composition alterations. However, PMS women displayed decreased delta incidence and increased theta incidence and amplitude during the electroencephalographic study [74].

\section{Leptin and the Growth Hormone Axis}

Leptin also participates in the pathophysiology of PMS through hypothalamic receptors that control general emotional behavior. This hormone is increased during the luteal phase in comparison to the follicular phase in women with and without PMS, but those who suffer premenstrual symptoms only have a significantly increased level in the follicular phase [75]. However, GnRH analogues do not influence leptin levels in both normal and PMS, suggesting that changes of leptin levels would not being important in the pathophysiology of PMS [76].

The growth hormone axis has also been studied in women with PMS or PMDD. Patients with major depression have somatotropic hormone alterations. Women with PMS had insulin-growth-like factor 1 (IGF-1), IGF-binding protein 3, estradiol and progesterone levels that did not differ between women with prospectively documented PMS and control subjects [77]. As compared to controls, women with PMDD have lower IGF-1, which was significantly lower throughout all phases of the menstrual cycle [78].

\section{Nutrition and Micro-Nutrients}

There is an intense interest concerning the effects of nutrients, psychological state, mental performance and wellbeing in PMS women. Energy consumption varies during human and animal reproductive cycles, with a nadir in the peri-ovular phase and a zenith in the luteal phase [79]. The pattern for the selection of certain foods has little consistency depending on gonadal hormones; nevertheless, changes in appetite, food cravings and calorie intake during the menstrual cycle have a certain parallelism with the serotonin rhythm. In the premenstrual phase, with low serotonin activity, there is a predisposition for the excessive consumption of food, cravings and depression. PMS has been linked with dysfunctional serotonin metabolism, and experimental evidence suggests that hormonal fluctuations do affect central serotonin levels $[80,81]$.

A vegetarian diet reduces pain, fluid retention, weight gain and premenstrual symptoms, while at the same time increasing the globulin that transports sex hormones [82]. Analysing specific vegetable consumption reveals that neither soybeans nor isoflavones produce changes in premenstrual symptoms; on the other hand, a diet rich in carbohydrates increases premenstrual symptoms [83].

PMS among overweight women may condition the type of nutrients and calories consumed in different phases of the menstrual cycle [84]. After making appropriate adjustments, during the premenstrual phase PMS women increase their consumption of fats, carbohydrates and simple sugars. This could explain the fact of increased weight at certain moments of the menstrual cycle, as referred by some PMS women.

Estrogens regulate calcium metabolism, its intestinal absorption, and parathormone secretion, causing fluctuations throughout the cycle [85]. On the other hand, hypo- and hypercalcemia are associated with emotional disorders. PMS and hypocalcemia symptoms are similar. Calcium supplements may improve mood and physical symptoms among PMS women. Compared to controls, PMDD women displayed lower ionised calcium during menses, and lower urine calcium excretion during the late follicular, mid-cycle and early luteal phases. In addition, 1, 25-dihydroxyvitamin D was significantly lower in the luteal phase of cases as compared to controls [86]. Further studies are needed since vitamin $\mathrm{D}$ is involved in many basic biological processes [87-90], including endocrine, cell and immune functions. Furthermore, low serum vitamin D levels have been found in mood disorders affecting women [91].

Serum calcium and vitamin D levels are lower in PMS women, and calcium supplementation may reduce symptom severity. In a nested case-control study within the prospective Nurses' Health Study II cohort, women aged 27 to 44, PMS free at baseline in 1991, were studied for the presentation of premenstrual symptoms and calcium and vitamin D intake. After adjusting for confounding factors, women in the highest quintile of total vitamin D intake had a significant lower relative risk for PMS compared with those in the lowest quintile. Calcium intake from food sources was also inversely related to PMS. Participants with the highest calcium intake had a lower relative risk [92].

In PMDD women calcium metabolism abnormalities may cause some affective and somatic symptoms. PMDD women displayed significantly lower ionized calcium at menses, lower urine calcium excretion (late follicular, midcycle and early luteal phase) and lower luteal phase serum vitamin $\mathrm{D}$, as compared to non PMDD control women [86].

Magnesium intercellular differences, in the presence of normal plasma levels, have been reported in PMS women $[93,94]$. However, such differences are not limited to the luteal phase, which renders difficulties in interpreting the role of magnesium in the pathophysiology of PMDD [95].

\section{Immunological Influences}

There are bidirectional link communications between the nervous and the immune system. Produced and released neurotransmitters/hormones interact with immune cells to alter immune functions, including cytokine production. At the same time, cytokines produced by immune/ nervous 
system cells regulate sleep. Emotional stability and modifications associated to natural killer (NK) cell activity modifications have also been studied [96]. In healthy subjects, anxiety and personality trait modulate NK response to psychological stress. Co-morbid anxiety and depression alter cellular immunity, and NK cell normalization is associated with successful pharmacotherapy [97]. Emotional changes are associated to subjective discomfort, significant catecholamines and cortisol increased concentrations, and to increased CD8+ and CD56+ cell counts. Induced stress is associated to different migration processes among these cells [98] that could be modulated by endocrine and nervous inputs. The influence of sex hormones on the immune system activity has been reported to be gender-associated and disappears after the menopause [99]. However, the precise links between cyclical premenstrual disorders and the immune system need specific research to determine if associations are causal or casual.

\section{Psychosocial Aspects}

In some women, menstrual cultural stereotypes may contribute to the development of premenstrual symptoms. Undoubtedly cultural attitudes, psychosocial experiences or expectations, and levels of stress influence the expression of symptoms. Tradition says that PMS occurs more frequently in psychically unstable women, those that may have a constitutional susceptibility characterized by an exaggerated response to various stimuli. PMS women have higher levels of anxiety, neuroticism, and negative attitudes toward their bodies, sex and masturbation [100-102]. Psychoanalytical theories have related PMS with a femininity complex, ambivalent desire for pregnancy and unresolved conflicts over sexual preferences. These approaches have been questioned from different perspectives [103, 104].

So-called secondary impulses or conditioned motivation have great importance in moulding personality; if a response is consistently reinforced, this behavior tends to appear with greater frequency until it becomes one of the main traits of personality. In some cultures, attitudes toward menstruation and premenstrual experiences among adolescents are moulded according to the experiences of older female members of the family who transmit negative messages and the perception that menstruation is weakening and annoying [104, 105].

PMDD women have a personal history of physical or sexual abuse. The latter present lower luteal phase basal norepinephrine levels as compared to their counterparts. Additionally they display more exaggerated reactions to stress in the luteal phase [106].

\section{CLINICAL MANAGEMENT}

When managing patients with variable symptoms presenting along the menstrual cycle which are suspicious of PMS or PMDD these should be differentiated from premenstrual exacerbation of other disorders. Specific diagnostic criteria for both PMS and PMDD should be supported by the precise identification of complaint and symptom diaries. For the clinical diagnosis of PMS, the American College of Obstetrics and Gynecology recommends the work-up proposed by the San
Diego University of California and the US National Institute of Mental Health [107]. The American Psychiatric Association criteria should be followed for diagnosis of women with suspected PMDD [8].

Specific diagnostic criteria should be supported by symptom diaries. Premenstrual symptom diaries for several consecutive months should be recorded in order to have details about cycle-to-cycle variability. The Moss Menstrual Distress Questionnaire allows to asses physical, emotional, and behavioral symptoms that accompany the menstrual cycle, and following up on the therapeutic effects of different treatments [108, 109]. Identification of cyclical symptoms may be obtained by completing the PRISM (Prospective Record of the Impact and Severity of Menstrual Symptoms) calendar every night for three consecutive cycles. On the first cycle women may complete several other psychometric measures. Using the PRISM, a minimal $66 \%$ increase in physical symptoms from the late follicular to the late luteal phase assign subjects to luteal phase physical symptoms (LPPS) and non-LPPS groups. The presentation of severe physical symptoms in the late luteal phase of the female reproductive cycle is not always accompanied by a worsening of psychological symptoms [110]. The Daily Record of Severity of Problems may detect differences along the menstrual cycle in order to determine the degree of symptomatic variation of associated premenstrual symptom $[111,112]$.

Women may be categorized in three groups, normal with no significant variations along the cycle, PMS, and PMDD cases, depending on the severity of premenstrual symptomatology $[70,113]$. Other similar scales can be used to study different aspects of menstrual cyclical disorders [114]. However, targeting women with specific premenstrual symptom scales, for specific treatment modalities, raises some concerns regarding the fact that the tools might improve response rates beyond the current ceiling of approximately $60 \%$ [115].

Many women suffering either PMS or PMDD are not diagnosed and treated. On the other hand, many others are given a label without a precise diagnosis. Those that are diagnosed are usually prescribed a medication. Placebo is significantly effective in PMS management. Thus, during PMS treatment, a significant response is commonly defined as a $50 \%$ reduction in symptom score, although this limit is empirical it seems to demonstrate the strong placebo effect of many therapeutic options $[39,116,117]$.

\section{TREATMENT}

Treatment of PMS or PMDD women is confined to reduce symptoms and improve social and occupational function in order to increase individual quality of life. There are three therapeutical approaches for PMS and PMDD: nutritional and lifestyle, pharmacological treatment and psycho-behavioral therapy. No scientific studies have been carried out to determine which approach is most effective.

Lifestyle changes may be useful in women with mild symptoms. Aerobic exercise and a healthy diet may improve premenstrual symptoms [118-120]. Eating foods with low 
glycemic index along with proteins in moderate amounts through the day prevents unstable blood sugar and mood swings during PMS. Women who eat only salads and vegetables are at risk of low protein levels and are prone to experience PMS symptoms. PMS management strategies should consider factors such as high stress, caffeine intake, and stop smoking. Since obesity has been associated to high premenstrual symptom prevalence, appropriate exercise and a hypocaloric diet should be recommended in women with elevated body weight.

Recent reviews have detailed therapeutic options for both PMS and PMDD women [29, 121-124]. In North America and the UK, antidepressive drugs are very popular, but this is not the case in Europe where hormone treatment, analgesics and phytotherapy are used. The U.S. Food and Drug Administration has now approved only four agents for the treatment of PMDD: fluoxetine, controlled-release paroxetine, sertraline and a $3 \mathrm{mg}$ drospirenone $/ 20-\mu \mathrm{g}$ ethinylestradiol oral contraceptive administered in a 24/4 regimen. In Europe and South America, there are more therapeutic agents than in North America. In Asia, different forms of traditional medicines have been used, although some methodological bias may be present in these studies.

SSRIs are most effective for irritability and anxiety symptoms than hormone therapy, whereas having lesser efficacy for 'atypical' premenstrual symptoms. An altered serotoninergic system in PMDD women may be the underlying mechanism for the observed symptoms; consequently treatment with SSRIs remains to date the preferred treatment. SSRI use has demonstrated treatment efficacy for the management of PMS/PMDD complaints, having a double response rate as compared to placebo. Both mood and physical symptoms improved with SSRIs, although the greatest improvement is obtained in irritability and mood swings while fatigue had less improvement [29, $121,122]$. The rapid action of SSRIs on premenstrual symptoms allow their used only during the 14 days of the luteal phase. It seems that all SSRIs are effective in intermittent luteal phase dosing. Starting treatment at the time of symptom initiation and stopping after menses initiation or 3 days later is a new strategy being studied which allows even shorter term treatments.

The duration of SSRI treatment for premenstrual symptoms is unknown and the rate of relapse with different SSRIs is also not well known. It seems that women with severe symptoms at baseline are more likely to relapse as compared to women in the lower symptom severity group [125].

Although the neuroleptic malignant syndrome (NMS) does appear to be rare, and the serotonin syndrome seems more prevalent, they are both connected with antidepressants. NMS involves muscle rigidity, fever and can cause delirium. Presence seems to increase in the first few weeks of anti-depressant use and upon dose changes. Serotonin syndrome, specially in its most severe form, and NMS are overlapping with regard to clinical features, and may not be distinguishable [126]. SSRIs, and selective serotonin/norepinephrine reuptake inhibitors (SNRIs), can cause an increase in serotonin levels. Symptoms of the serotonin syndrome may include restlessness, hallucinations, loss of coordination, fast heart beat, rapid changes in blood pressure, increased body temperature, overactive reflexes, nausea, vomiting, and diarrhea.

A very used gynecological therapeutical approach has been to produce anovulation. Thus, ovulation suppression ameliorates a broad range of behavioral as well as physical premenstrual complaints. Antigonadotropic agents (e.g., $\mathrm{GnRH}$, danazol, steroid implants) and oral contraceptives that inhibit ovulation should be effective for the treatment of PMS/PMDD. However, on occasions women with severe symptoms do not achieve relief and sometimes may even become worse $[4,29,49,117,125]$.

Low dose GnRH agonist treatment in women with severe PMS significantly decreased levels of allopregnanolone and progesterone in parallel with symptom improvement. Same women who responded to placebo during placebo phase displayed lower serum allopregnanolone concentrations than GnRH agonist responders. This was associated with improvement in symptoms compared with pre-treatment ratings. Thus, treatment response, whether induced by the GnRH agonists or placebo, appears to be associated with a decrease in allopregnanolone concentrations [127].

The hypo-estrogenic state induced by GnRH agonist treatment renders them less suitable for long-term clinical use. A meta-analysis [128] supports the feasibility of addback therapy, although some patients report a recurrence of symptoms with add-back estrogen/progestagen treatment [129]. Segebladh et al. [130] evaluated three different addback hormone replacement treatments in PMDD women who were treated with a GnRH agonist. Add-back treatments consisted of $1.5 \mathrm{mg}$ estradiol and $400 \mathrm{mg}$ progesterone, 1.5 $\mathrm{mg}$ estradiol and placebo, and $0.5 \mathrm{mg}$ estradiol and $400 \mathrm{mg}$ progesterone. The highest dose of estradiol associated with progesterone treatment was associated with the most pronounced symptom recurrence. As an alternative, combining a GnRH agonist with continuous treatment with tibolone may prove to be effective [128, 131].

Combined oral contraceptives may produce PMS-like symptoms, including water retention and irritability. Negative symptoms are one of the major reasons for discontinuation of combined oral contraceptives. These adverse effects are related to progestogen properties. However, the prevalence of psychiatric disorders and PMDD symptoms is high in women with adverse mood changes during oral contraceptive treatments. Thus, it has been reported that women with ongoing or past self-reported adverse mood effects had an increased rate of mood disorders [132].

The new progestagen drospirenone -a spironolaclactone analog- has been included in contraceptive pills, profiting its ability to reduce symptoms of water retention and other side effects related to androgen excess. Drospirenone has antimineralocorticoid and antiandrogenic properties $[49,117]$. The new oral contraceptive including 24 pills containing ethinylestradiol $(20 \mu \mathrm{g})$ and drospirenone $(3 \mathrm{mg} /$ day), followed 
by 4 days of inactive pills, is associated with lower endocrine endogenous fluctuations which may reduce perimenstrual discomfort [133]. In addition, drospirenone has diuretic and antihypertensive antiandrogenic effects similar to its related compound spironolactone. Long-cycle treatment with a combined oral contraceptive has been proposed to reduce the fluctuations associated to the conventional 7-day free hormone period. Increasing the duration of active hormone intake to 24 days and shortening the hormone-free interval to 4 days, causes greater ovarian activity suppression as compared with the conventional 21/7 treatment. No difference was observed between the 24/4 and the conventional 21/7 regimen in progesterone levels. In addition as compared to the 21-day regimen, the 24-day treatment scheme produced a more consistent suppression of endogenous estradiol and reduced hormone fluctuations [134]. Continuous daily treatment with a monophasic pill $(20 \mu \mathrm{g}$ ethinylestradiol and $1 \mathrm{mg}$ norethindrone acetate) produced in women a significant reduction of symptoms and improvement in behavior, compared to traditional cyclical treatment [113].

Non-steroidal anti-inflammatory drugs (NSAIDs), nutritional supplements and herbal medicines have been used to treat premenstrual symptoms associated with PMS or PMDD [29, 135-137]. Taken before, or at the onset of menstruation, NSAIDs such as ibuprofen or naproxen sodium can ease cramping and breast discomfort. Consuming dietary and daily calcium supplementation may reduce PMS and PMDD physical and emotional symptoms [85, 86, 138]. Vitamin B-6 and magnesium also may benefit in some cases [137, 139, 140]. Clinical trials suggest that L-tryptophan, chasteberry (Vitex agnus-castus), soy isoflavones, and saffron (Crocus sativus L.) may reduce irritability, mood swings, anger and headaches associated with PMDD [136, 141, 142]. However, there are controversial results concerning the efficacy of these treatments [143-145], specially when considering severe symptoms. Other treatments, like acupuncture [146] have not been confirmed in controlled trials.

Cognitive-behavioral therapy can enhance self-esteem and social integration as well as reduce other symptoms [147]. All kinds of psychotherapy can be relevant [148], even though relaxation technique training may be particularly suitable [149].

\section{FINAL REMARKS}

Every woman has had some symptoms of PMS that present shortly before the menstruation. But when symptoms associated with the menstrual cycle become so severe that they interfere with daily activities and quality of life, the PMDD may be diagnosed. In spite of the generalization of the diagnosis criteria, PMS and PMDD remain complex and polymorphous disorders. PMS was considered for a long time as a somatic disease, but now psychiatric symptom severity most often justifies the medical care. In order to distinguish some isolated and mild complaints form the disabling disorder, standardized prospective auto-assessment is the most relevant method to achieve a proper diagnosis. Healthy lifestyle, exercise, SSRIs and the new oral contraceptive (24/4 regimen ethinylestradiol/drospirenone) appear to be the most effective treatments. Herbal products and alternative therapies may be also used, although the level of evidence is low or controversial. However, no single intervention has proven to be effective in all PMS or PMDD patients.

\section{ACKNOWLEDGEMENTS}

This research has been partially supported by the B/017543/08 AECID ("Agencia Española de Cooperación Internacional para el Desarrollo") grant from the Spanish "Ministerio de Asuntos Exteriores y Cooperación".

\section{REFERENCES}

[1] World Health Organization. The ICD-10 Classification of mental, behavioral and developmental disorders. $10^{\text {th }}$ ed. Geneva: World Health Organization 1996.

[2] Kraemer GR, Kraemer RR. Premenstrual syndrome: diagnosis and treatment experiences. J Womens Health 1998; 7: 893-907.

[3] Freeman EW. Premenstrual syndrome and premenstrual dysphoric disorder: definitions and diagnosis. Psychoneuroendocrinology 2003; 28(Suppl 3): 25-37.

[4] Pérez-López FR. Psiconeuroendocrinología del síndrome premenstrual. Progr Obstet Ginecol 2005; 48(Suppl 2): 1211-5.

[5] Mishell DR, Jr. Premenstrual disorders: epidemiology and disease burden. Am J Manag Care 2005; 11: S473-9.

[6] Campagne DM, Campagne G. The premenstrual syndrome revisited. Eur J Obstet Gynecol Reprod Biol 2007; 130: 4-17.

[7] American Psychiatric Association. Diagnostic and Statistical Manual of Mental Disorders, DSM-III-R; Washington: American Psychiatric Association Inc 1987.

[8] American Psychiatric Association. Diagnostic and statistical manual of mental disorders: DSM-IV. $4^{\text {th }}$ ed. Washington, D.C.: American Psychiatric Association 1994.

[9] Pearlstein T, Yonkers KA, Fayyad R, Gillespie JA. Pretreatment pattern of symptom expression in premenstrual dysphoric disorder. J Affect Disord 2005; 85: 275-82.

[10] De Ronchi D, Ujkaj M, Boaron F, Muro A, Piselli M, Quartesan R. Symptoms of depression in late luteal phase dysphoric disorder: a variant of mood disorder? J Affect Disord 2005; 86: 169-74.

[11] Moynihan R, Heath I, Henry D. Selling sickness: The pharmaceutical industry and disease mongering. BMJ 2002; 324: 886-91.

[12] Mintzes B. Disease mongering in drug promotion: do governments have a regulatory role? PLoS Med 2006; 3: e198.

[13] The European Agency for the Evaluation of Medicinal Products. Committee for Proprietary Medicinal Products. EMEA/CPMP/ 3263/03. [cited 6 June 2009]. Available from: http://www.emea.eu ropa.eu/pdfs/human/referral/prozac/326303en.pdf

[14] National Prescribing System. Australia. [cited 6 June 2009]. Available from: http://www.nps.org.au/

[15] Cohen LS, Soares CN, Otto MW, Sweeney BH, Liberman RF, Harlow BL. Prevalence and predictors of premenstrual dysphoric disorder (PMDD) in older premenopausal women: the Harvard Study of moods and cycles. J Affect Disord 2002; 70: 125-32.

[16] Halbreich U. The etiology, biology, and evolving pathology of premenstrual syndromes. Psychoneuroendocrinology 2003; 28(Suppl 3): 55-99.

[17] Howe J. BBC. National Association for Premenstrual Syndrome. [cited 9 April 2009]. Available from: http://news.bbc.co.uk/1/hi/ health/7797607.stm

[18] Potter J, Bouyer J, Trussell J, Moreau C. Premenstrual syndrome prevalence and fluctuation over time: results from a french population-based survey. J Womens Health (Larchmt) 2009; 18: 31-9.

[19] Gehlert S, Song IH, Chang C-H, Hartlage SA. The prevalence of premenstrual dysphoric disorder in a randomly selected group of urban and rural women. Psychol Med 2009; 39: 129-36.

[20] Gray AJ. Stigma in psychiatry. J Roy Soc Med 2002; 95: 72-6.

[21] Perkonigg A, Yonkers KA, Pfister H, Lieb R, Wittchen HU. Risk factors for premenstrual dysphoric disorder in a community sample of young women: the role of traumatic events and posttraumatic stress disorder. J Clin Psychiatry 2004; 65: 1314-22.

[22] Payne JL, Klein SR, Zamoiski RB, et al. Premenstrual mood symptoms: study of familiality and personality correlates in mood disorder pedigrees. Arch Womens Ment Health 2009; 12: 27-34. 
[23] Woods NF, Lentz M, Mitchell ES, Heitkemper M, Shaver J. PMS after 40: persistence of a stress-related symptom pattern. Res Nurs Health 1997; 20: 319-40.

[24] Girdler SS, Klatzkin R. Neurosteroids in the context of stress: implications for depressive disorders. Pharmacol Ther 2007; 116: 125-39.

[25] Golding JM, Taylor DL, Menard L, King MJ. Prevalence of sexual abuse history in a sample of women seeking treatment for premenstrual syndrome. J Psychosom Obstet Gynaecol 2000; 21: 69-80.

[26] Girdler SS, Leserman J, Bunevicius R, Klatzkin R, Pedersen CA, Light KC. Persistent alterations in biological profiles in women with abuse histories: influence of premenstrual dysphoric disorder. Health Psychol 2007; 26: 201-13.

[27] Nakamoto Y, Sato M, Miwa M, Murakami M, Yoshii M. Impaired reactivity to mental stress in premenstrual dysphoric disorder [PMDD] patients. Neurosci Res 2007; 58(Suppl 1): S165

[28] Masho SW, Adera T, South-Paul J. Obesity as a risk factor for premenstrual syndrome. J Psychosom Obstet Gynaecol 2005; 26: 33-9.

[29] Cunningham J, Yonkers KA, O'Brien S, Eriksson E. Update on research and treatment of premenstrual dysphoric disorder. Harv Rev Psychiatry 2009; 17: 120-37.

[30] Damberg M, Westberg L, Berggård C, et al. Investigation of transcription factor AP-2 beta genotype in women with premenstrual dysphoric disorder. Neurosci Lett 2005; 377: 49-52.

[31] Damberg M. Transcription factor AP-2 and monoaminergic functions in the central nervous system. J Neural Transm 2005; 112: $1281-96$.

[32] Condon JT. The premenstrual syndrome: a twin study. Br J Psychiatry 1993; 162: 481-6.

[33] Kendler KS, Karkowski LM, Corey LA, Neale MC. Longitudinal population-based twin study of retrospectively reported premenstrual symptoms and lifetime major depression. Am J Psychiatry 1998; 155: 1234-40.

[34] Treloar SA, Heath AC, Martin NG. Genetic and environmental influences on premenstrual symptoms in an Australian twin sample. Psychol Med 2002; 32: 25-38.

[35] Huo L, Straub RE, Roca C, et al. Risk for premenstrual dysphoric disorder is associated with genetic variation in ESR1, the estrogen receptor alpha gene. Biol Psychiatry 2007; 62: 925-33.

[36] Magnay JL, Ismail KM, Chapman G, Cioni L, Jones PW, O'Brien $\mathrm{S}$. Serotonin transporter, tryptophan hydroxylase, and monoamine oxidase A gene polymorphisms in premenstrual dysphoric disorder. Am J Obstet Gynecol 2006; 195: 1254-9.

[37] Dhingra V, Magnay JL, O'Brien PM, Chapman G, Fryer AA, Ismail KM. Serotonin receptor $1 \mathrm{~A} \mathrm{C}(-1019) \mathrm{G}$ polymorphism associated with premenstrual dysphoric disorder. Obstet Gynecol 2007; 110: 788-92.

[38] Hsiao CC, Liu CY, Hsiao MC. No correlation of depression and anxiety to plasma estrogen and progesterone levels in patients with premenstrual dysphoric disorder. Psychiatry Clin Neurosci 2004; 58: 593-9

[39] Reed SC, Levin FR, Evans SM. Changes in mood, cognitive performance and appetite in the late luteal and follicular phases of the menstrual cycle in women with and without PMDD premenstrual dysphoric disorder. Horm Behav 2008; 54: 185-93.

[40] Poromaa SI, Smith S, Gulinello M. GABA receptors, progesterone and premenstrual dysphoric disorder. Arch Womens Ment Health 2003; 6: 23-41.

[41] Backstrom T, Andersson A, Andree L, et al. Pathogenesis in menstrual cycle-linked CNS disorders. Ann NY Acad Sci 2003; 1007: 42-53.

[42] Smith S, Ruderman Y, Frye C, Homanics G, Yuan M. Steroid withdrawal in the mouse results in anxiogenic effects of 3alpha, 5beta-THP: a possible model of premenstrual dysphoric disorder. Psychopharmacology (Berl) 2006; 186: 323-33.

[43] Birzniece V, Backstrom T, Johansson IM, et al. Neuroactive steroid effects on cognitive functions with a focus on the serotonin and GABA systems. Brain Res Rev 2006; 51: 212-39.

[44] Schmidt P, Nieman L, Danaceau M, Adams L, Rubinow D. Differential behavioral effects of gonadal steriods in women with and in those without premenstrual syndrome. N Engl J Med 1998; 338: $209-16$
[45] Wyatt K, Dimmock P, Jones P, Obhrai M, O'Brien S. Efficacy of progesterone and progestogens in management of premenstrual syndrome: systematic review. BMJ 2001; 323: 776-80.

[46] Oelkers WK. Effects of estrogens and progestogens on the reninaldosterone system and blood pressure. Steroids 1996; 61: 166-71.

[47] Olson BR, Forman MR, Lanza E, et al. Relation between sodium balance and menstrual cycle symptoms in normal women. Ann Intern Med 1996; 125: 564-7.

[48] Parsey KS, Pong A. An open-label, multicenter study to evaluate Yasmin, a low-dose combination oral contraceptive containing drospirenone, a new progestogen. Contraception 2000; 61: 105-11.

[49] Pérez-López FR. Clinical experiences with drospirenone: from reproductive to postmenopausal years. Maturitas 2008; 60: 78-91

[50] Gulinello M, Smith SS. Anxiogenic effects of neurosteroid exposure: sex differences and altered GABAA receptor pharmacology in adult rats. J Pharmacol Exp Ther 2003; 305: 5418.

[51] Rapkin AJ, Morgan M, Goldman L, Brann DW, Simone D, Mahesh VB. Progesterone metabolite allopregnanolone in women with premenstrual syndrome. Obstet Gynecol 1997; 90: 709-14.

[52] Monteleone $\mathrm{P}$, Luisi S, Tonetti A, et al. Allopregnanolone concentrations and premenstrual syndrome. Eur J Endocrinol 2000; 142: 269-73.

[53] Girdler SS, Straneva PA, Light KC, Pedersen CA, Morrow AL. Allopregnanolone levels and reactivity to mental stress in premenstrual dysphoric disorder. Biol Psychiatry 2001; 49: 788-97.

[54] Lombardi I, Luisi S, Quirici B, et al. Adrenal response to adrenocorticotropic hormone stimulation in patients with premenstrual syndrome. Gynecol Endocrinol 2004; 18: 79-87.

[55] Schmidt P, Purdy R, Moore P, Paul S, Rubinow D. Circulating levels of anxiolytic steroids in the luteal phase in women with premenstrual syndrome and in control subjects. J Clin Endocrinol Metab 1994; 79: 1256-60.

[56] Matsumoto K, Puia G, Dong E, Pinna G. GABA(A) receptor neurotransmission dysfunction in a mouse model of social isolation-induced stress: possible insights into a nonserotonergic mechanism of action of SSRIs in mood and anxiety disorders. Stress 2007; 10: 3-12.

[57] Sundstrom I, Andersson A, Nybery S, Ashbrook D, Purdy RH, Backstrom T. Patients with premenstrual syndrome have a different sensitivity to a neuroactive steroid during the menstrual cycle compared to control subjects. Neuroendocrinology 1998; 67: 12638.

[58] Le Melledo J-M, Van Driel M, Coupland NJ, Lott P, Jhangri GS. Response to flumazenil in women with premenstrual dysphoric disorder. Am J Psychiatry 2000; 157: 821-3.

[59] Blum I, Lerman M, Misrachi I, et al. Lack of plasma norepinephrine cyclicity, increased estradiol during the follicular phase, and of progesterone and gonadotrophins at ovulation in women with premenstrual syndrome. Neuropsychobiology 2004; 50: $10-5$

[60] Gurguis GN, Yonkers KA, Phan SP, Blakeley JE, Williams A, Rush AJ. Adrenergic receptors in premenstrual dysphoric disorder: I. Platelet alpha 2 receptors: Gi protein coupling, phase of menstrual cycle, and prediction of luteal phase symptom severity. Biol Psychiatry 1998; 44: 600-9.

[61] Inoue $\mathrm{Y}$, Terao $\mathrm{T}$, Iwata $\mathrm{N}$, et al. Fluctuating serotonergic function in premenstrual dysphoric disorder and premenstrual syndrome: findings from neuroendocrine challenge tests. Psychopharmacology (Berl) 2007; 190: 213-9.

[62] Dimmock PW, Wyatt KM, Jones PW, O'Brien PM. Efficacy of selective serotonin-reuptake inhibitors in premenstrual syndrome: a systematic review. Lancet 2000; 356: 1131-6.

[63] Pearlstein T. Selective serotonin reuptake inhibitors for premenstrual dysphoric disorder: the emerging gold standard? Drugs 2002; 62: 1869-85.

[64] Epperson CN, Haga K, Mason GF, et al. Cortical gammaaminobutyric acid levels across the menstrual cycle in healthy women and those with premenstrual dysphoric disorder: a proton magnetic resonance spectroscopy study. Arch Gen Psychiatry 2002; 59: 851-8

[65] Smith MJ, Adams LF, Schmidt PJ, Rubinow DR, Wassermann EM. Abnormal luteal phase excitability of the motor cortex in women with premenstrual syndrome. Biol Psychiatry 2003; 54: 757-62.

[66] Batra NA, Seres-Mailo J, Hanstock C, et al. Proton magnetic resonance spectroscopy measurement of brain glutamate levels in 
premenstrual dysphoric disorder. Biol Psychiatry 2008; 63: 117884.

[67] Chae Y, Kim HY, Lee HJ, et al. The alteration of pain sensitivity at disease-specific acupuncture points in premenstrual syndrome. J Physiol Sci 2007; 57: 115-9.

[68] Protopopescu X, Butler T, Pan H, et al. Hippocampal structural changes across the menstrual cycle. Hippocampus 2008; 18: 985-8.

[69] Kondo M, Hirano T, Okamura Y. Changes in autonomic nerve function during the normal menstrual cycle measured by the coefficient of variation of R-R intervals. Nippon Sanka Fujinka Gakkai Zasshi 1989; 41: 513-8.

[70] Matsumoto T, Ushiroyama T, Morimura M, et al. Autonomic nervous system activity in the late luteal phase of eumenorrheic women with premenstrual symptomatology. J Psychosom Obstet Gynaecol 2006; 27: 131-9.

[71] Girdler SS, Pedersen CA, Straneva PA, et al. Dysregulation of cardiovascular and neuroendocrine responses to stress in premenstrual dysphoric disorder. Psychiatry Res 1998; 81: 163-78.

[72] Landén M, Wennerblom B, Tygesen H, et al. Heart rate variability in premenstrual dysphoric disorder. Psychoneuroendocrinology 2004; 29: 733-40.

[73] Baker FC, Colrain IM, Trinder J. Reduced parasympathetic activity during sleep in the symptomatic phase of severe premenstrual syndrome. J Psychosom Res 2008; 65: 13-22.

[74] Baker FC, Kahan TL, Trinder J, Colrain IM. Sleep quality and the sleep electroencephalogram in women with severe premenstrual syndrome. Sleep 2007; 30: 1283-91.

[75] Anim-Nyame N, Domoney C, Panay N, Jones J, Alaghband-Zadeh J, Studd JW. Plasma leptin concentrations are increased in women with premenstrual syndrome. Hum Reprod 2000; 15: 2329-32.

[76] Tommaselli GA, Di Carlo C, Bifulco G, et al. Serum leptin levels in patients with premenstrual syndrome treated with GnRH analogues alone and in association with tibolone. Clin Endocrinol (Oxf) 2003; 59: 716-22.

[77] Rapkin AJ, Cedars M, Morgan M, Goldman L. Insulin-like growth factor-1 and insulin-like growth factor-binding protein-3 in women with premenstrual syndrome. Fertil Steril 1998; 70: 1077-80.

[78] Thys-Jacobs S, McMahon D, Bilezikian JP. Lower insulin-like growth factor-1 concentrations in women with premenstrual dysphoric disorder. Am J Obstet Gynecol 2008; 198(5): 506.e1-8.

[79] Dye L, Blundell JE. Menstrual cycle and appetite control: implications for weight regulation. Hum Reprod 1997; 12: 114251.

[80] Wyatt KM, Drimmock PW, O’Brien PMS. Selective serotonin reuptake inhibitors for premenstrual syndrome. The Cochrane Library. Oxford, England: Update Software 1999.

[81] Dye L, Lluch A, Blundell JE. Macronutrients and mental performance. Nutrition 2000; 16: 1021-34.

[82] Barnard ND, Scialli AR, Hurlock D, Bertron P. Diet and sexhormone binding globulin, dysmenorrhea, and premenstrual symptoms. Obstet Gynecol 2000; 95: 245-50.

[83] Nagata C, Hirokawa K, Shimizu N, Shimizu H. Soy, fat and other dietary factors in relation to premenstrual symptoms in Japanese women. BJOG 2004; 111: 594-9.

[84] Cross GB, Marley J, Miles H, Willson K. Changes in nutrient intake during the menstrual cycle of overweight women with premenstrual syndrome. Br J Nutr 2001; 85: 475-82.

[85] Thys-Jacobs S. Micronutrients and the premenstrual syndrome: the case for calcium. J Am Coll Nutr 2000; 19: 220-7.

[86] Thys-Jacobs S, McMahon D, Bilezikian JP. Cyclical changes in calcium metabolism across the menstrual cycle in women with premenstrual dysphoric disorder. J Clin Endocrinol Metab 2007; 92: 2952-9.

[87] Pérez-López FR. Vitamin D: the secosteroid hormone and human reproduction. Gynecol Endocrinol 2007; 23: 13-24.

[88] Pérez-López FR. Sunlight, the vitamin D endocrine system, and their relationships with gynaecologic cancer. Maturitas 2008; 59: 101-13.

[89] Pérez-López FR, Chedraui P, Haya J. Vitamin D acquisition and breast cancer risk. Reprod Sci 2009; 16: 7-19.

[90] Pérez-López FR. Vitamin D metabolism and cardiovascular risk factors in postmenopausal women. Maturitas 2009; 62: 248-62.

[91] Murphy PK, Wagner CL. Vitamin D and mood disorders among women: an integrative review. J Midwifery Womens Health 2008; 53: 440-6.
[92] Bertone-Johnson ER, Hankinson SE, Bendich A, Johnson SR, Willett WC, Manson JE. Calcium and vitamin D intake and risk of incident premenstrual syndrome. Arch Intern Med 2005; 165: 1246-52.

[93] Sherwood R, Rocks B, Stewart A, Saxton R. Magnesium and the premenstrual syndrome. Ann Clin Biochem 1986; 23: 667-70.

[94] Facchinetti F, Borella P, Fioroni L, et al. Reduction of monocyte's magnesium in patients affected by premenstrual syndrome. J Psychosom Obstet Gynaecol 1990; 11: 221.

[95] Rosenstein D, Elin R, Hosseini J, Grover G, Rubinow D. Magnesium measures across the menstrual cycle in premenstrual syndrome. Biol Psychiatry 1994; 35: 557-61.

[96] Borella P, Bargellini A, Rovesti S, et al. Emotional stability, anxiety, and natural killer activity under examination stress. Psychoneuroendocrinology 1999; 24: 613-27.

[97] Ravindran AV, Griffiths J, Merali Z, Anisman H. Circulating lymphocyte subsets in major depression and dysthymia with typical or atypical features. Psychosom Med 1998; 60: 283-9.

[98] Hennig J, Netter P, Voigt KH. Cortisol mediates redistribution of $\mathrm{CD} 8+$ but not of CD56 + cells after the psychological stress of public speaking. Psychoneuroendocrinology 2001; 26: 673-87.

[99] Giglio T, Imro MA, Filaci G, et al. Immune cell circulating subsets are affected by gonadal function. Life Sci 1994; 54: 1305-12.

[100] Limosin F, Ades J. Psychiatric and psychological aspects of premenstrual syndrome. Encephale 2001; 27: 501-8.

[101] Ross C, Coleman G, Stojanovska C. Relationship between the NEO personality inventory revised neuroticism scale and prospectively reported negative affect across the menstrual cycle. J Psychosom Obstet Gynaecol 2001; 22: 165-76.

[102] Bailey JW, Cohen LS. Prevalence of mood and anxiety disorders in women who seek treatment for premenstrual syndrome. J Womens Health Gend Based Med 1999; 8: 1181-4.

[103] Greer G. The change. Women, ageing and the menopause. New York: Alfred A. Knopf 1992.

[104] Houppert K. The curse: Confronting the last taboo, menstruation. London: Profile 2000.

[105] Anson O. Exploring the bio-psycho-social approach to premenstrual experiences. Soc Sci Med 1999; 49: 67-80.

[106] Girdler SS, Sherwood A, Hinderliter AL, et al. Biological correlates of abuse in women with premenstrual dysphoric disorder and healthy controls. Psychosom Med 2003; 65: 849-56.

[107] ACOG Practice Bulletin. Clinical management guidelines for obstetrician-gynecologists. Number 15. Premenstrual syndrome. Obstet Gynecol 2000; 95: 1-9.

[108] Moos R. Menstrual Distress Questionnaire Manual. Palo Alto, CA: Stanford University and Veterans Administration Hospital 1977.

[109] Marsh DM, Donald M, Dougherty DM, Moeller FG, Swann AC, Spiga R. Laboratory-measured aggressive behavior of women: Acute tryptophan depletion and augmentation. Neuropsychopharmacology 2002; 26: 660-71.

[110] Gonda X, Telek T, Juhász G, Lazary J, Vargha A, Bagdy G. Patterns of mood changes throughout the reproductive cycle in healthy women without premenstrual dysphoric disorders. Prog Neuropsychopharmacol Biol Psychiatry 2008; 32: 1782-8.

[111] Endicott J, Nee J, Harrison W. Daily record of severity of problems (DRSP): reliability and validity. Arch Womens Ment Health 2006; 9: 41-9.

[112] Borenstein JE, Dean BB, Leifke E, Korner P, Yonkers KA. Differences in symptom scores and health outcomes in premenstrual syndrome. J Womens Health (Larchmt) 2007; 16: 1139-44.

[113] Legro RS, Pauli JG, Kunselman AR, et al. Effects of continuous versus cyclical oral contraception: a randomized controlled trial. J Clin Endocrinol Metab 2008; 93: 420-9.

[114] Coffee AL, Kuehl TJ, Sulak PJ. Comparison of scales for evaluating premenstrual symptoms in women using oral contraceptives. Pharmacotherapy 2008; 28: 576-83.

[115] Halbreich U, O'Brien PM, Eriksson E, Bäckström T, Yonkers KA, Freeman EW. Are there differential symptom profiles that improve in response to different pharmacological treatments of premenstrual syndrome/premenstrual dysphoric disorder? CNS Drugs 2006; 20: 523-47.

[116] Mitwally MF, Kah LS, Halbreich U. Pharmacotherapy of premenstrual syndromes and premenstrual disphoric disorder: current practices. Expert Opin Pharmacother 2002; 3: 1577-90. 
[117] Pérez-López FR. Drospirenona de la etapa reproductiva a la postmenopausia. Revista Iberoamericana Educación Médica Continuada 2009; 27: (in press).

[118] Prior JC, Vigna Y, Sciarretta D, Alojado N, Schulzer M. Conditioning exercise decreases premenstrual symptoms: a prospective, controlled 6-month trial. Fertil Steril 1987; 47: 402-8.

[119] Sayegh R, Schiff I, Wurtman J, Spiers P, McDermott J, Wurtman $\mathrm{R}$. The effect of a carbohydrate-rich beverage on mood, appetite, and cognitive function in women with premenstrual syndrome. Obstet Gynecol 1995; 86: 5208 .

[120] Stoddard JL, Dent CW, Shames L, Bernstein L. Exercise training effects on premenstrual distress and ovarian steroid hormones. Eur J Appl Physiol 2007; 99: 27-37.

[121] Jarvis CI, Lynch AM, Morin AK. Management strategies for premenstrual syndrome/premenstrual dysphoric disorder. Ann Pharmacother 2008; 42: 967-78

[122] Brown J, O'Brien PM, Marjoribanks J, Wyatt K. Selective serotonin reuptake inhibitors for premenstrual syndrome. Cochrane Database Syst Rev 2009; 2: CD001396.

[123] Wyatt K, Dimmock P, O'Brien P. Selective serotonin reuptake inhibitors for premenstrual syndrome. Cochrane Database Syst Rev 2002; 4: CD001396.

[124] Shah NR, Jones JB, Aperi J, Shemtov R, Karne A, Borenstein J. Selective serotonin reuptake inhibitors for premenstrual syndrome and premenstrual dysphoric disorder: a meta-analysis. Obstet Gynecol 2008; 111: 1175-82.

[125] Freeman EW, Rickels K, Sammel MD, Lin H, Sondheimer SJ. Time to relapse after short- or long-term treatment of severe premenstrual syndrome with sertraline. Arch Gen Psychiatry 2009; 66: 537-44.

[126] FDA. Combined use of 5-hydroxytryptamine receptor agonists (Triptans), Selective Serotonin Reuptake Inhibitors (SSRIs) or Selective Serotonin/Norepinephrine Reuptake Inhibitors (SNRIs) may result in life-threatening serotonin syndrome. [cited 6 June 2009]. Available from: http://www.fda.gov/Drugs/DrugSafety/ PublicHealthAdvisories/ucm 124349.htm

[127] Nyberg S, Bäckström T, Zingmark E, Purdy RH, Poromaa IS. Allopregnanolone decrease with symptom improvement during placebo and gonadotropin-releasing hormone agonist treatment in women with severe premenstrual syndrome. Gynecol Endocrinol 2007; 23: 257-66.

[128] Wyatt K, Dimmock P, Ismail K, Jones P, O'Brien P. The effectiveness of GnRHa with and without 'add-back' therapy in treating premenstrual syndrome: a meta analysis. BJOG 2004; 6: 585-93.

[129] Leather A, Studd J, Watson N, Holland E. The treatment of severe premenstrual syndrome with goserelin with and without "addback" estrogen therapy: a placebo-controlled study. Gynecol Endocrinol 1999; 13: 48-55.

[130] Segebladh B, Borgström A, Nyberg S, Bixo M, SundströmPoromaa I. Evaluation of different add-back estradiol and progesterone treatments to gonadotropin-releasing hormone agonist treatment in patients with premenstrual dysphoric disorder. Am J Obstet Gynecol 2009; (in press).

[131] Di Carlo C, Palomba S, Tommaselli G, Guida M, Sardo A, Nappi C. Use of leuprolide acetate plus tibolone in the treatment of severe premenstrual syndrome. Fertil Steril 2001; 75: 380-4.

[132] Segebladh B, Borgström A, Odlind V, Bixo M, SundströmPoromaa I. Prevalence of psychiatric disorders and premenstrual dysphoric symptoms in patients with experience of adverse mood during treatment with combined oral contraceptives. Contraception 2009; 79: 50-5.

[133] Lopez LM, Kaptein AA, Helmerhorst FM. Oral contraceptives containing drospirenone for premenstrual syndrome. Cochrane Database Syst Rev 2009; 2: CD006586.

[134] Klipping K, Duijkers I, Trummer D, Marr J. Suppression of ovarian activity with a drospirenone-containing oral contraceptive in a $24 / 4$ regimen. Contraception 2008; 78: 16-25

[135] Johnson WG, Carr-Nangle RE, Bergeron KC. Macronutrient intake, eating habits, and exercise as moderators of menstrual distress in healthy women. Psychosom Med 1995; 57: 324-30.

[136] Schellenberg R. Treatment for the premenstrual syndrome with agnus castus fruit extract: prospective, randomised, placebo controlled study. BMJ 2001; 322: 134-7

[137] Bhatia SC, Bhatia SK. Diagnosis and treatment of premenstrual dysphoric disorder. Am Fam Physician 2002; 66: 1239-48.

[138] Ward MW, Holimon TD. Calcium treatment for premenstrual syndrome. Ann Pharmacother 1999; 33: 1356-8.

[139] Wyatt KM, Dimmock PW, Jones PW, Shaughn O'Brien PM. Efficacy of vitamin B-6 in the treatment of premenstrual syndrome: systematic review. BMJ 1999; 318: 1375-81.

[140] Facchinetti F, Borella P, Sances G, Fioroni L, Nappi RE, Genazzani AR. Oral magnesium successfully relieves premenstrual mood changes. Obstet Gynecol 1991; 78: 177-181.

[141] Bryant M, Cassidy A, Hill C, Powell J, Talbot D, Dye L. Effect of consumption of soy isoflavones on behavioral, somatic and affective symptoms in women with premenstrual syndrome. $\mathrm{Br} \mathrm{J}$ Nutr 2005; 93: 731-9.

[142] Agha-Hosseini M, Kashani L, Aleyaseen A, et al. Crocus sativus L. (saffron) in the treatment of premenstrual syndrome: a doubleblind, randomised and placebo-controlled trial. BJOG 2008; 115: 515-9.

[143] Hagen I, Nesheim BI, Tuntland T. No effect of vitamin B-6 against premenstrual tension. A controlled clinical study. Acta Obstet Gynecol Scand 1985; 64: 667-70

[144] Hicks SM, Walker AF, Gallagher J, Middleton RW, Wright J. The significance of "nonsignificance" in randomized controlled studies a discussion inspired by a double-blinded study on St. John's wort (Hypericum perforatum L.) for premenstrual symptoms. J Altern Complement Med 2004; 10: 925-32.

[145] Khine K, Rosenstein DL, Elin RJ, Niemela JE, Schmidt PJ, Rubinow DR. Magnesium (mg) retention and mood effects after intravenous $\mathrm{mg}$ infusion in premenstrual dysphoric disorder. Biol Psychiatry 2006; 59: 327-33.

[146] Taguchi R, Matsubara S, Yoshimoto S, Imai K, Ohkuchi A, Kitakoji H. Acupuncture for premenstrual dysphoric disorder. Arch Gynecol Obstet 2009; (in press).

[147] Christensen AP, Oei TP. The efficacy of cognitive behavior therapy in treating premenstrual dysphoric changes. J Affect Disord 1995; 33: 57-63.

[148] Busse JW, Montori VM, Krasnik C, Patelis-Siotis I, Guyatt GH Psychological intervention for premenstrual syndrome: a metaanalysis of randomized controlled trials. Psychother Psychosom 2009; 78: 6-15.

[149] Dvivedi J, Dvivedi S, Mahajan KK, Mittal S, Singhal A. Effect of '61-points relaxation technique' on stress parameters in premenstrual syndrome. Indian J Physiol Pharmacol 2008; 52: 6976. 